\title{
Improving Physicians' Adherence to Guidelines Regarding Antibiotics Use in Acute Upper Respiratory Tract Infections in Adult Patients Attending Ministry of Health Hospitals in Alexandria, Egypt: An Interventional Study
}

\author{
Sarah K Amer ${ }^{1 *}$, Ramez N Bedwani ${ }^{2}$, Gihan M Shehata ${ }^{2}$ and Alaa Abouelfetouh ${ }^{3}$ \\ ${ }^{1}$ Department of Pharmaceutical Sciences, Faculty of Pharmacy, Arab Academy for Science, Technology and Maritime Transport, Alexandria, Egypt \\ ${ }^{2}$ Department of Biomedical Informatics and Medical Statistics, Medical Research Institute, Alexandria University, Egypt \\ ${ }^{3}$ Department of Microbiology and Immunology, Faculty of Pharmacy, Alexandria University, Egypt
}

\begin{abstract}
Background: Antibiotic resistance, as a major public health problem, has its roots in the irrational use of antibiotics, consequently causing treatment failure. It is commonly seen in treating acute upper respiratory tract infections. AURTI include sinusitis, pharyngitis and bronchitis. Adherence to guidelines is not completely afforded due to poor knowledge of physicians in management of AURTI. They fail to perform a definite differentiation between the viral and the bacterial type of the infection. Also patients affect physicians' prescribing habits; as patients feel satisfied being prescribed antibiotics.
\end{abstract}

Aim: This study aims to increase physicians' adherence to current clinical guidelines for AURTI regarding the use of antibiotics

Methods: A predesigned questionnaire was used for the assessment of the physicians' adherence to the guidelines before and after the intervention. Active and passive interventions to improve physicians' adherence to guidelines as short - session for physicians of didactic teaching and antibiotic guideline posters in respiratory unit clinics. Throat swab using Rapid Strep A Test strip (RADT)

Conclusion: Using active and passive interventions can change prescribing habits. Physicians' adherence to guidelines will be perceptible, resulting in improvement of appropriate antibiotic use for AURTI, reduction of unnecessary healthcare costs and advance in quality of care provided by outpatient clinics. Physicians' qualifications and the use of RADT in Pharyngeal Infection play a significant role affecting the adherence to guidelines and prescribing of the proper antibiotic.

Keywords: Respiratory tract infections; Antibiotics; Healthcare

\section{Introduction}

Antibiotic resistance, as a major public health problem, has its roots in the irrational use of antibiotics, consequently causing treatment failure. It is commonly seen in treating of acute upper respiratory tract infections. AURTI include sinusitis, pharyngitis and bronchitis. The adherence to guidelines is not completely afforded due to poor knowledge of physicians for management of AURTI. They fail to perform a definite differentiation between the viral and the bacterial type of the infection. Consequently antibiotics are irrationally prescribed regardless the guideline rules. Also patients affect physicians' prescribing habits; as patients feel satisfied being prescribed antibiotics. Using active and passive interventions can change prescribing habits. Physicians' adherence to guidelines will be perceptible, resulting in improvement of appropriate antibiotic use for AURTI, reduction of unnecessary healthcare costs and advance in quality of care provided by outpatient clinics. The impact of continued awareness and managed care in hospitals will be substantially seen on all health care providers and patients. Physicians' behavior will be changed; they will be more adherent to guidelines regarding diagnosis and clinical decision for appropriate treatment regimen not urgently containing antibiotics unless they are desperately needed. Patients' high antibiotic resistance rates will be decreased and patient's overall health will be increased. In the hospital the census rate due to antibiotic resistance will be reduced. The treatment cost will be also consequently reduced $[1,2]$.

\section{Materials and Methods}

This study is an intervention study. The study was done in The
ENT and chest outpatient clinics of six Ministry of Health Hospitals in Alexandria, Egypt (Ras Eltin, Abou Kir, Elgomhoreya, Elamreya, Elagami and Bourg Elarab) covering the six districts of Alexandria. The target population was physicians in outpatient clinics responsible for treating socio- economic equally patients with acute upper respiratory tract infections (including sinusitis, pharyngitis and bronchitis). Sample Size Calculation was done Using PASS program version 12, a minimum number of 61 physicians is required using paired test to compare two proportions (before and after) according to hypothetical values of $50 \%$ and $75 \%$ adherence rate before and after respectively, at $80 \%$ power and $5 \%$ level of significance. The Sampling Technique was clustered as following Appendix 1. These 450 prescriptions were assessed before and after the interventions. This means the overall number of prescriptions in our study before and after were 900 prescriptions. The study included adult patients in age from 18 years to 40 years old and

*Corresponding author: Amer SK, Pharmaceutical Sciences Department, Faculty of Pharmacy, Arab Academy for Science, Technology and Maritime Transport, Alexandria, Egypt, Tel: 20233365491; Fax: 20233365492; E-mail: sarah7amer8@gmail.com

Received January 06, 2018; Accepted February 19, 2018; Published February 26, 2018

Citation: Amer SK, Bedwani RN, Shehata GM, Abouelfetouh A (2018) Improving Physicians' Adherence to Guidelines Regarding Antibiotics Use in Acute Upper Respiratory Tract Infections in Adult Patients Attending Ministry of Health Hospitals in Alexandria, Egypt: An Interventional Study. J Microb Biochem Technol 10: 16-19. doi: 10.4172/1948-5948.1000389

Copyright: @ 2018 Amer SK, et al. This is an open-access article distributed under the terms of the Creative Commons Attribution License, which permits unrestricted use, distribution, and reproduction in any medium, provided the original author and source are credited. 
Citation: Amer SK, Bedwani RN, Shehata GM, Abouelfetouh A (2018) Improving Physicians' Adherence to Guidelines Regarding Antibiotics Use in Acute Upper Respiratory Tract Infections in Adult Patients Attending Ministry of Health Hospitals in Alexandria, Egypt: An Interventional Study. J Microb Biochem Technol 10: 16-19. doi: 10.4172/1948-5948.1000389

acute Upper Respiratory Tract Infections; defined as infections that involve paranasal sinuses, pharynx and bronchi. The illness is known as sinusitis, pharyngitis and bronchitis, respectively. Onset of symptoms occurs from one to three days after exposure to the infectious agent. If the infectious agent is of viral origin then symptoms would last for less than ten days, while if it is a bacterial infection then symptoms would last more than ten days.

Excluded from the study were patients with chronic upper respiratory tract infections, patients less than 18 years in age, immunocompromised patients, renal impairment patients, hepatic impairment patients and lower respiratory tract infections

A predesigned questionnaire was used for the assessment of the physicians' adherence to the guidelines before and after the intervention. It collected data about the physicians, hospitals, patients' diagnosis and the type of treatment prescribed. Also, we performed active and passive interventions to improve physicians' adherence to guidelines in the form of short-session for physicians of didactic teaching and antibiotic guideline posters in respiratory unit clinics. (Appendices 2a2c). Throat swabs were done using Rapid Strep A Test strip (RADT) to distinguish between bacterial and viral respiratory infections. Statistical Analysis was done through two steps; data processing and data analysis. Data Processing was done by performing data check and recoding of variables. Data Analysis was done by using IBM SPSS Software Package Version 20.0. [3]. The quantitative variables were summarized using mean and standard deviation; the only quantitative variable in our study was age of the patients. The qualitative variables were summarized using numbers and percent. The qualitative variables that were summarized were: the gender of the patients, the qualifications of the physicians, the adherence rates before and after the intervention, the antibiotic prescription rates before and after the intervention and the use of rapid antigen strep A test (RADT) after the intervention. Comparisons between dependent groups regarding categorical variables were tested using McNemar's test to assess the adherence rate before and after the intervention. Significance of the obtained results was judged at the $5 \%$ level (2-sided).

Ethical approval was obtained from Medical Research Institute before the beginning of the research data collection. Approval was obtained from Ministry of Health hospitals where the study was conducted. All study participants were informed and declared their approval in the participation of the questionnaire. Confidentiality was

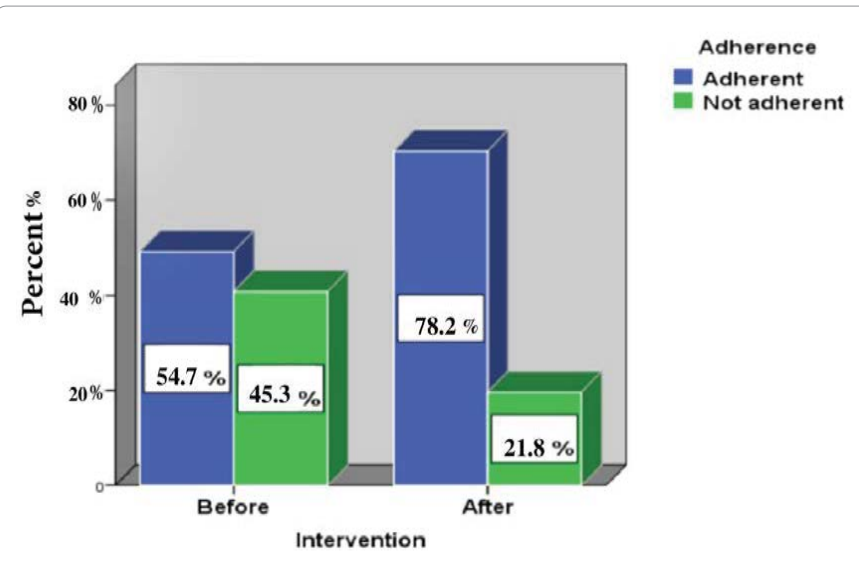

Figure 1: The overall adherence rate to guidelines before and after the intervention in the three types of AURTIs in Ministry of Health General hospitals in Alexandria, Egypt. ensured for participating physicians and patients. An informed consent was taken from physicians and patients.

\section{Results}

Adherence rate to guidelines before and after the intervention in the three types of acute upper respiratory tract infections is presented in Figure 1 showing; that there was a significant improvement in the adherence rate to guidelines regarding the use of antibiotics in AURTI which was seen in the six Ministry of Health hospitals. The overall adherence rate in all the hospitals together were improved from $54.7 \%$ to $78.2 \%$ and this improvement was statistically significant (McNemar test, $\mathrm{p}=0.000$ )

Adherence rate in each type of infection before and after the intervention is presented in Table 1. The Table illustrates the overall adherence in Sinusoidal, Pharyngeal and Bronchial infections before and after the intervention. The overall adherence rate in all hospitals together in Sinusoidal Infection was improved from 52.7\% to $76.7 \%$ and this improvement was statistically significant $(\mathrm{p}=0.000)$. The same significant improvement was seen in overall adherence rate in all hospitals together in Pharyngeal Infection from $54.7 \%$ to $78.7 \%$. Also, a significant improvement was noticed in Bronchial Infection from $56.7 \%$ to $79.3 \%$.

Factors affecting adherence rate to the guidelines before and after the intervention are qualification of the physicians and the use of rapid antigen strep A Test (RADT) by the physicians in Pharyngeal Infection. Table 2 clarifies, that there was a border line significant difference $(\mathrm{p}=0.065)$ regarding the physicians' qualifications. This precipitates as

\begin{tabular}{|c|c|c|c|c|c|c|}
\hline \multirow{3}{*}{$\begin{array}{l}\text { Type of AURT } \\
\text { Infection }\end{array}$} & \multirow{3}{*}{ Intervention } & \multicolumn{4}{|c|}{ Adherence } & \multirow{3}{*}{$\begin{array}{c}\text { McNemar } \\
\text { test } \\
\text { (p-value) }\end{array}$} \\
\hline & & \multicolumn{2}{|c|}{ Adherent } & \multicolumn{2}{|c|}{ Not adherent } & \\
\hline & & No & $\%$ & No & $\%$ & \\
\hline Sinusoidal infection & Before $(n=150)$ & 79 & $52.70 \%$ & 71 & $47.30 \%$ & \multirow{2}{*}{0} \\
\hline$(n=300)$ & After $(n=150)$ & 115 & $76.70 \%$ & 35 & $23.30 \%$ & \\
\hline Pharyngeal infection & Before $(n=150)$ & 82 & $54.70 \%$ & 68 & $45.30 \%$ & \multirow{2}{*}{0} \\
\hline$(n=300)$ & After $(n=150)$ & 118 & $78.70 \%$ & 32 & $21.30 \%$ & \\
\hline Bronchial infection & Before $(n=150)$ & 85 & $56.70 \%$ & 65 & $43.30 \%$ & \multirow{2}{*}{0} \\
\hline$(n=300)$ & After $(n=150)$ & 119 & $79.30 \%$ & 31 & $20.70 \%$ & \\
\hline
\end{tabular}

Table 1: Adherence rate to guidelines before and after the intervention in each type of upper respiratory tract infections in Ministry of Health General hospitals in Alexandria, Egypt.

\begin{tabular}{|c|c|c|c|c|c|}
\hline \multirow{3}{*}{$\begin{array}{l}\text { Factors affecting } \\
\text { adherence rate }\end{array}$} & \multicolumn{4}{|c|}{ Adherence } & \multirow{3}{*}{$\begin{array}{c}\text { McNemar test } \\
\text { (p-value) }\end{array}$} \\
\hline & \multicolumn{2}{|c|}{ Before } & \multicolumn{2}{|c|}{ After } & \\
\hline & No & $\%$ & No & $\%$ & \\
\hline \multicolumn{6}{|c|}{ Physicians Qualification } \\
\hline Bachelor & 53 & $37.80 \%$ & 106 & $75.70 \%$ & \multirow{3}{*}{0.065} \\
\hline Master & 106 & $58.90 \%$ & 136 & $75.60 \%$ & \\
\hline PhD & 87 & $66.90 \%$ & 110 & $84.60 \%$ & \\
\hline \multicolumn{6}{|l|}{ Use of RADT test } \\
\hline \multicolumn{6}{|l|}{ Bachelor $(n=45)$} \\
\hline$\S$ Used $(n=40)$ & 33 & $82.50 \%$ & 7 & $17.50 \%$ & \multirow{2}{*}{0.002} \\
\hline$\S$ Not Used $(n=5)$ & 1 & $20 \%$ & 4 & $80 \%$ & \\
\hline \multicolumn{6}{|l|}{ Master $(n=60)$} \\
\hline$\S$ Used $(n=25)$ & 23 & $92 \%$ & 2 & $8 \%$ & \multirow{2}{*}{0.017} \\
\hline$\S$ Not Used $(n=35)$ & 23 & $65.70 \%$ & 12 & $34.30 \%$ & \\
\hline \multicolumn{6}{|l|}{$\operatorname{PhD}(n=45)$} \\
\hline$\S$ Used $(n=30)$ & 26 & $86.70 \%$ & 4 & $13.30 \%$ & \multirow{2}{*}{0.056} \\
\hline$\S$ Not Used $(n=15)$ & 12 & $80 \%$ & 3 & $20 \%$ & \\
\hline
\end{tabular}

Table 2: Factors affecting adherence rate to the guidelines before and after the intervention. 
a factor affecting the adherence rate among the AURTIs. All physicians; despite their qualification showed an improvement in their adherence rate to the guidelines after the intervention. The best improvement was observed among bachelor degree physicians, followed by the master degree physicians and the least improvement was among $\mathrm{PhD}$ physicians.

Table 2 also explains that, the availability of rapid antigen strep A test (RADT) could increase the adherence rate to guidelines in the Pharyngeal Infection. The bachelor degree physicians were the most likely to use the RADT; resulting in higher significant adherence rate $(82.5 \%)$ than those not used RADT $(20 \%)$ (McNemar test, $\mathrm{p}=0.002$ ). Followed by the master degree physicians; they also showed a significant higher adherence rate due to the use of RADT (92\%) than those not used RADT (65.7\%) ( $\mathrm{p}=0.017$ ). While among $\mathrm{PhD}$ degree physicians the adherence rate among those used the RADT and not used RADT were $86.7 \%$ and $80 \%$, respectively with borderline significance ( $\mathrm{p}=0.056$ ). This is explained by the attitude of those Physicians to depend on their clinical experience in the diagnosis and prescribing than relying on the use of RADT.

\section{Discussion}

\section{Overall adherence rate}

In our study we evaluated the physicians' adherence rate to the guidelines according to the symptoms duration to distinguish between viral and bacterial infections to ensure a proper diagnosis. Adherence was defined by antibiotic prescription for symptoms persisting for more than 10 days, confirming a bacterial infection or no antibiotic prescription for symptoms persisting for less than 10 days and hence confirming a viral infection diagnosis. While non-adherence was considered when: Symptoms lasted for less than 10 days and antibiotic treatment was prescribed. In agreement with our study; a study done in Egypt stated that the main obstacle confronting the adherence lies in the challenge of reaching the proper diagnosis in outpatient clinics in classifying the type of the disease either viral of bacterial. Consequently high rates of antibiotic abuse are reached [4]. Contradicting to our study, some studies assessed the adherence in terms of the type of antibiotic prescribed in respiratory outpatient clinics without considering the symptoms duration that differentiates bacterial and viral infection. They only focused on the unnecessary and improper use of antibiotics, e.g. antibiotics that are prescribed for viral infections and broad-spectrum antibiotics, that are frequently prescribed when narrow-spectrum ones are needed [5,6]. Our study revealed that an improvement in physicians' attitude towards proper diagnosis of the infection type was seen after the guideline sessions and posters. Conclusively, a significant improvement from $54.7 \%$ to $78.2 \%$ was achieved in the adherence rate towards the guidelines. It is worth mentioning that during the 1980s and 1990 Egypt began a training program for good management of ARIs. The program included 115 government physicians. The assessment demonstrated the impact of training in the use of clinical practice guidelines. In contrast to our study the previous training program didn't show any significant improvement, it only showed a little effect. Poor management was still seen in misclassification and differentiation between disease types leading to inappropriate treatment [7]. In Spain 2012, it was found that there is a high rate of discrepancies between clinical practice and evidence-based management of RTIs seen in more than half of the patients visiting RTIs outpatient clinics referring for the importance of the use of clinical guidelines [8]. The establishing of guidelines aims to increase physicians' adherence and assists them to make decisions on treating specified conditions of URTI as sinusitis, pharyngitis, bronchitis in adult outpatients [9].

\section{Adherence rate in each type of URTIs}

In our study, we noticed that in Sinusoidal Infection; The overall adherence rate in all hospitals together was significantly improved from $52.7 \%$ to $76.7 \%$ ( $\mathrm{p}=0.000$ ). Another study done in Egypt found that the adherence to the guidelines in sinusitis is quite difficult as it depends on clinical criteria rather than a diagnostic test; therefore; there is a significant heterogeneity in how this diagnosis is made [10]. A study was performed in Northern Saudi Arabia in 2000 claiming that half of the antibiotic prescriptions for RTIs were not in accordance with guideline recommendations. Overprescribing was highest for adults between 18 and 65 years of age [11]

Significant improvement in the adherence to guidelines in Pharyngeal infection was observed in our study with overall improvement rate from $54.7 \%$ to $78.7 \%(\mathrm{p}=0.000)$. This indicates the importance of establishing programs for the guidelines in increasing the adherence rate. In agreement with our results Bisno et al. [12] emphasized that establishing of guidelines aims to assist the physicians to make decisions on treating specified conditions of URTI as pharyngitis in adult respiratory outpatient clinics.

Our study revealed that the intervention precipitated a vast improvement in the adherence to guidelines was also seen in the Bronchial infection similar to other AURTIs, Sinusitis and Pharyngitis. Physicians' attitude was evaluated in another past study; and considerable differences in prescribing pattern between physician categories were found. The greatest differences were seen in management of acute bronchitis, where guidelines recommend avoidance of antibiotics [5]. The current findings emphasize that guideline posters and sessions could have a great impact on improving the physicians' adherence for better care to be provided in respiratory outpatient clinics.

Our study detected only two factors affecting the adherence rate to guidelines; physicians' qualifications and the use of RADT in pharyngitis. Another study done in Egypt (2014) showed that patients preference for an antibiotic to be prescribed is a significant factor associated with physician's antibiotic prescribing; acting as an influence factor [13]. A study done in Boston emphasizing that clinician's fear failing to meet patient expectations and demand for being prescribed an antibiotic [14]. In agreement with the results at hand, Gröndal [15] reported in 2015 that, the past Swedish guidelines stated that rapid antigen strep A test (RADT) for Group A Streptococci reduce unnecessary antibiotics prescribed to outpatients with pharyngitis. In France, a study assessed the use of rapid antigen diagnostic tests and their impact on antibiotics prescribing behavior of physicians for outpatients with acute pharyngitis [16].

\section{Limitations of the study}

The physicians were allowed to base the disease type either viral or bacterial only on their own clinical interpretation of signs and symptoms of patients. Therefore, this item was a subjective measure depending on personal judgment. Some physicians prescribed antibiotics in order to fulfill outpatients' satisfaction which is not true. It is difficult to change ingrained personal and cultural prescribing habits of the physicians against a background of satisfying the patient.

\section{Strengths of the study}

The strength of our study is the large sample size of 900 prescriptions covering the complete range of adult patients attending outpatient clinics of Ministry of Health Hospitals. Another point of strength is the number of posters that were made available in outpatient 
Citation: Amer SK, Bedwani RN, Shehata GM, Abouelfetouh A (2018) Improving Physicians' Adherence to Guidelines Regarding Antibiotics Use in Acute Upper Respiratory Tract Infections in Adult Patients Attending Ministry of Health Hospitals in Alexandria, Egypt: An Interventional Study. J Microb Biochem Technol 10: 16-19. doi: 10.4172/1948-5948.1000389

clinics containing the updated American Family Physicians Guidelines concerning the use of antibiotics in acute upper respiratory tract infections. A third point of strength was offering of RADT for free to ensure its availability in outpatient clinics to let the physicians use it and be part of their clinical decision making strategy. Also, short sessions, where given to physicians, who did not use the test before, to familiarize them with it and stress its importance.

\section{Conclusion}

Using active and passive interventions can change prescribing habits and physicians' adherence to guidelines; resulting in improvement of appropriate antibiotics use for AURTI and reduction of unnecessary healthcare prescribed antibiotics and advance in quality of care provided by outpatient clinics. Physicians qualifications plays a significant role where; first/second year residents tend to follow guidelines and prescribe appropriately antibiotics while older residents and staff rely mainly on their practical experience. Also the use of RADT can improve the adherence rate in Pharyngeal Infection.

\section{References}

1. Pierson DJ (2001) The future of respiratory care. Respir Care 46: 705-718.

2. Douce FH. The future of the respiratory care profession In: Burton GG, Hodgkin JE, Ward JJ, editors. Respiratory Care.

3. Kirkpatrick LA, Feeney BC (2013) A simple guide to IBM SPSS statistics for version 20.0. Student ed. Belmont, Calif: Wadsworth, Cengage Learning.

4. Koura M, Khairy A, Abdel-Aal N, Deghedi B, Sabra A(1998) Quality assessment of the primary health care services provided for ARI control in Alexandria. J Egypt Public Health Assoc 74: 275-296.

5. Wong DM, Blumberg DA, Lowe LG (2006) Guidelines for the use of antibiotics in acute upper respiratory tract infections. Am Fam Physician 6: 956-66.

6. Dekker AR, Verheij TJ, van der Velden AW (2015) Inappropriate antibiotic prescription for respiratory tract indications: Most prominent in adult patients Fam Pract 32: 401-407.

7. Langsten RL, el-Mougi M, Black RE (2005) Impact of training on assessment of diarrhea and acute respiratory infection at government health facilities in Egypt. J Health Popul Nutr 23: 282-291.

8. Sangrador CO, De Dios JG (2012) Management of acute bronchiolitis in emergency wards in Spain: Variability and appropriateness analysis (aBREVIADo Project). Eur J Pediatr 171: 1109-1119.

9. Dooling KL, Kandeel A, Hicks LA, El-Shoubary W, Fawzi K, et al. (2014) Understanding antibiotic use in Minya district, Egypt: Physician and pharmacist prescribing and the factors influencing their practices. Antibiotics 3: 233-243.

10. El Gilany A (2000) Acute respiratory infections in primary health care centres in northern Saudi Arabia.

11. Bisno AL, Gerber MA, Kaplan EL, Schwartz RH (1997) Diagnosis and management of group A streptococcal pharyngitis: A practice guideline. Clin Infect Dis 25: $574-583$

12. Kandeel A, El-Shoubary W, Hicks LA, Fattah MA, Dooling KL, et al. (2014) Patient attitudes and beliefs and provider practices regarding antibiotic use for acute respiratory tract infections in Minya, Egypt. Antibiotics 3: 632-644.

13. Dempsey PP, Businger AC, Whaley LE, Gagne JJ, Linder JA (2014) Primary care clinicians' perceptions about antibiotic prescribing for acute bronchitis: A qualitative study. BMC Fam Pract 15: 194.

14. Gröndal H, Hedin K, Strandberg EL, André M, Brorsson A (2015) Near-patient tests and the clinical gaze in decision-making of Swedish GPs not following current guidelines for sore throat - A qualitative interview study. BMC Fam Pract p: 81.

15. Pajot M, Asseray N, Leux C, Senand R, Garnier F, et al. (2010) Use of rapid diagnostic tests of tonsillitis in medical practice. Survey conducted from November 2006 to January 2007 in Pays de la Loire (France). Presse Med 39: $77-85$.

16. Pulcini C, Pauvif L, Paraponaris A, Verger P, Ventelou B (2012) Perceptions and attitudes of French general practitioners towards rapid antigen diagnostic tests in acute pharyngitis using a randomized case vignette study. J Antimicrob Chemother p: 73. 